\section{Acknowledgements}

The work was done while LI HUOGEN was a visiting scholar at Swedish University of Agricultural Science in Umeå. We gratefully thank Dr. TIM MUluIN and Milan LSTIBŮREK for support with the breeding simulator POPSIM including a version that accommodates this study and their comments. We also gratefully acknowledge financial support from the Kempe Foundation and the China Scholarship Council (CSC).

\section{Literature cited}

Andersson, E. W., K. A. Spanos, T. J. Mullin and D. LindGREN (1998a): Phenotypic selection can be better than selection for breeding value. Scand. J. For. Res. 13: 7-11.

Andersson, E. W., K. A. Spanos, T. J. Mullin and D. LindGREN (1998b): Phenotypic selection compared to restricted combined index selection for many generations. Silva Fennica 32(2): 111-120.

BurTon, G.W. (1974a): Recurrent restricted phenotypic selection increases forage yields of Pensacola bahiagrass. Crop Sci. 14: 831-835.

BuRTON, G. W. (1974b): Improved recurrent restricted phenotypic selection increases Bahiagrass forage yields. Crop Sci. 22: 1058-1061.

Cockerham, C. C. (1967): Group inbreeding and coancestry. Genetics 56: 89-104.

CotTerill, P. P. (1986): Gentic gains from alternative breeding strategies including simple low cost options. Silvae Genet. 35: 212-223.

DANUSEVIČIUS, D. and D. LINDGREN (2005): Optimisation of breeding population size for long-term breeding. Scandinavian Journal Forest Research (20) 1: 18-25.
Dempfle, L. (1990): Problems in the use of the relationship matrix in animal breeding. In: Advances in statistical methods for genetic improvement of livestock. (ed. D. Gianola and K. Hammond). Pp. 454-473. SpringerVerlag, Berlin.

FALCONER, D. S. (1989): Introduction to Quantitative Genetics, $3^{\text {rd }}$ edition. Longman, Scientific and Technical.

Lindgren, D., L. D. Gea and P. A. Jefferson (1996): Loss of genetic diversity monitored by status number. Silvae Genetica 45: 52-59.

LINDGREN, D. (2003): Low-input tree breeding strategies. In: Eucalyptus plantations-Research, Management and Development, R.-P. WEI and D. XU (eds), World scientific, Singapore, 146-149.

LSTIBŮREK M, 2005: Population response to positive assortative mating in forest tree breeding, $\mathrm{PhD}$ dissertation. North Carolina State University, Raleigh. USA.

Mullin, T. J. and Y. S. PARK (1995): Stochastic simulation of population management strategies for tree breeding: a new decision support tool for tree personal computers. Silvae Genet. 44: 132-141.

Rosvall, O. (1999): Enhancing gain from long-term forest tree breeding while conserving genetic diversity. Ph.D Thesis. Swedish University of Agricultural Sciences, Department of Forest Genetics and Plant Physiology, Umeå.

WEI, R.-P. and D. LINDGREN (1991): Selection effects on diversity and gain. Silva Fennica 25(4): 229-234.

WEI, R.-P. and D. LINDGREN (1993): Phenotypic selection was more efficient than combined index selection when applied on full sibs of lodgepole and Scots pine. Dept. of Forest Genetics and Plant Physiology, SUAS Report 11: 289-292.

\title{
Phenotypic Correlation and Path Coefficient Analysis of Nut Yield and Yield Components in Cashew (Anacardium occidentale L.).
}

\author{
By O. M. Aliyu
}

\author{
Department of Plant Breeding, Cocoa Research Institute of Nigeria, P M B 5244, Ibadan, Nigeria \\ walealiyu@mail.com
}

(Received $4^{\text {th }}$ July 2005)

\begin{abstract}
Relationships between cashew nut yield and nine agronomic traits comprising seven reproductive (nut and floral) and two vegetative characters were studied in 59 selected cashew genotypes over three production seasons. Phenotypic correlation analysis showed that nuts per panicle $(\mathrm{r}=0.844)$, number of nuts per tree $(\mathrm{r}=$ 0.988 ) and number of hermaphrodite flowers per panicle $(\mathrm{r}=0.863)$ were positively correlated with nut yield and could be used as primary components for improving yield. Although correlation analysis showed insignifi-
\end{abstract}

cant association between nut weight and nut yield, path analysis revealed that the trait had significant positive direct effect (0.317) on nut yield. The subtle indirect effects of nut weight and leaf size on nut yield were more important than their direct effects and could be classified as secondary components. Both the direct and indirect effects of weight of the whole fruit and tree canopy on nut yield were negative and appeared detrimental.

Key words: Anacardium occidentale, Correlation analysis, Path analysis, Breeding. 


\section{Introduction}

Cashew (Anacardium occidentale L.) is a tropical nut crop that belongs to the family Anacardiaceae, which consists of about 75 genera and 700 species (NAKASONE and PAULL, 1998). BeHRENS (1998) described cashew as a tropical tree species that originated from South and Central America. The tree is widely cultivated in many tropical countries of the world. The crop was introduced to India, Asia, and Africa in the $15^{\text {th }}$ and $16^{\text {th }}$ centuries (WoOdroof, 1967; OHLER, 1979). It is believed that cashew nut was brought into Africa from the northern part of South America by Portuguese missionaries in 1400 (Mitchell and MoRI, 1987). The crop has spread for over 500 years either naturally or through smallholder's cultivation. As smallholder crop in Africa, cashew is usually grown as a mono-crop or intercropped with food crops such as cassava, groundnuts, sesame, beans, maize, melon and sorghum. It was estimated that about 3 millions households in Africa were involved in cashew nut production with an average acreage of 3 hectares cashew trees.

Cashew is an evergreen perennial with dense foliage and can grow as high as 15 meters or more. Flowering normally occurs following the growth flush at the end of wet season and panicles are produced at the end of new shoots with majority at the periphery of the tree canopy. The panicle usually contains both male and hermaphrodite flowers in varying proportion. Cashew is an outbreeder and predominantly pollinated by insects, although some self-compatible and self-fertile ones had been reported (NoRTHWOOD, 1966; MASAWE, 1994; Freitas and PAXTON, 1996; AliYu, 2004). The kidney shaped nut is the true fruit of the cashew and is attached to the bottom of the apple. The kernel is protected by a hard shell or endocarp and a spongy mesocarp which contains the cashew nut shell liquid (CNSL). CNSL has a number of industrial uses especially in the manufacturing of brake linings, paints and vanishes etc. The juicy apple is usually yellow, orange or red in colour and high in vitamin A and C. In Africa, cashew apples are eaten fresh or made into alcohol but most of them are not used. The fruits drop to the ground, collected every few days and the nuts detached from the apples. The harvested nuts are sun dried as high moisture content can cause deterioration in kernel quality through mould, bacteria or enzyme activity.

In Africa, cashew gained economic importance after 1920s. Thereafter, cashew nut production in Africa increased substantially and became one of the major export crops for some of the African countries especially Mozambique and Tanzania. In the period between 1950 and 1970, the African continent as a whole supplied $70 \%$ of cashew nut production annually (SHOMARI and TOPPER, 2003). In the recent years, cultivation has extended to other countries including Benin, Ghana, Guinea Bissau, Kenya, Madagascar, Nigeria and Togo. The world cashew production has continued to increase steadily over the years, while Africa's share drastically diminished and this has been principally attributed to low tree yields. Cashew tree populations in Africa comprise mostly low yielding trees. Little work has been done to improve the yield potential of African cashew trees. Tree yields in farmers' field have been found to be highly varied such that, some trees may yield nothing whilst the best usually produced over $20 \mathrm{~kg}$ (MARTIN and KASUGa, 1995; AliYu, 2004). MARTIN et al. (1998) found that at least $70 \%$ yield came from an half of those productive trees in a farmer's field, while $30 \%$ yield resulted from another half of unproductive trees.

One of the primary objectives of cashew breeders is to increase the nut yield. Generally, yield represents the final character resulting from many developmental and biochemical processes which occur between germination and maturity. Before yield improvements can be realized, the breeder needs to identify the causes of variability in nut yield in any given environment. Since fluctuation in environment generally affects yield primarily through its components, many researchers have analyzed yield through its components (ADAMS, 1967; MCNEAL et al., 1974; ISHAQ et al., 2000; EsAN and OMOLAJA, 2002). GRAFIUS (1960) suggested that individual yield components may contribute valuable information in breeding for yield. Yield when viewed from the mechanistic or geometric point of view is a product of its components. Knowledge of the association between traits being improved e.g. yield and other traits in the population is desirable to a plant breeder. This will enable him to know how the selection pressure exerted by him on one trait will cause changes in other traits. Furthermore, the direction and magnitude of such changes could be made manifest. Traits associated with yield may be used either as indirect selection criteria or in a selection index for higher yield.

Statistical methods which have been developed to quantify relationships among traits in crop plants are correlation and regression analyses. Correlation analysis quantifies the relationships between any given pair of traits without regards to cause/effect relationship. Multiple regression analysis could be used to predict the performance of a dependent or resultant variable such as nut yield on the basis of a given set of independent or causal variables (DRAPER and SMITH, 1967; JACKSON, 1967). Despite the predictive role played by various multiple regression models, the interrelationships among causal variables cannot be clearly elucidated by multiple regression analysis. Path coefficient analysis can be used to get over the limitations of the first two techniques. Path analysis is a standardized partial regression analysis and was developed by WRIGHT (1921, 1923). It is useful in partitioning the correlation coefficients into direct effect through a given causal variable and indirect effects through alternate pathways (other causal variables).

The objective of this study was to quantify the phenotypic relationship between nut yield and nine other agronomic traits in cashew, on which data were collected for three production seasons, in order to gain representative results for efficient future selection and improvement.

\section{Materials and Methods}

Fifty-nine accessions comprising three selected populations (eleven clones from a farmer's farm in Ochaja, 
Kogi State; twenty-three Indian introductions from the plantations of Western Nigerian Development Corporation in Eruwa and Upper Ogun in Oyo State and Iwo in Osun State; and twenty-five Brazilian introductions from Kosoni-Ola Farm Limited, Oro, Kwara State) were established in the cashew research plots of Cocoa Research Institute of Nigeria (CRIN), Ibadan. The selected genotypes were evaluated over three production seasons (1999-2002). The materials were planted in a randomized complete block layout consisting of three replicates. Each accession was represented by three entries per block and they were planted at a spacing of $10 \mathrm{~m} \times 10 \mathrm{~m}$ in 1988 .

Data were collected on reproductive traits; nut weight (NWT), number of nuts per panicle (NNP), number of nuts per tree (NNT), nut yield in kg per tree (NYT), weight of a whole fruit (WWF), number of hermaphrodite flowers per panicle (HFP), pollen grain fertility (PGF) and days to flower anthesis (DFA); and on vegetative traits; tree canopy spread (TCS) and leaf size (LSZ) using the Descriptor for Cashew by International Board for Plant Genetic Resources (IBPGR 1986). Data on number of nuts per panicle (NNP) and number of hermaphrodite flowers per panicle (HFP) were collected from 40 panicles/inflorescences, randomly selected across the four cardinal positions of the tree canopy for each variable.

Data were summarized and statistically analysed for correlation coefficient analysis using 8.0 version of SAS software package. Path coefficient analysis was done following the procedure outlined by KIM and KoHOUT (1975), LI (1981) and SingH and CHAUDHARY (1985). The technique permitted the evaluation of the direct causal effect or path coefficient $P_{i y}$ of a cause $i$ on an effect $y$ i.e. nut yield and indirect effect of that cause through another causal variable $j$. A single direct effect (unidirectional pathway) is quantitatively equal to $P_{i y}$ while an indirect effect through alternate pathway is expressed as pathway $P_{j y}$ x correlation coefficient $r_{i j}$ of various agronomic traits on nut yield. Total indirect effects $I$ is the sum of individual indirect effects. The effect coefficient $C$ is the sum of direct and total indirect effects of a causal variable. Non causal correlation or residual $E$ is the coefficient of total correlation minus effect coefficient.

\section{Results}

The summary of the phenotypic correlations among yield and nine agronomic traits is presented in Table 1. The highest positive correlation was found between nut yield and nuts per tree $(r=0.99)$, while the most significant negative association was between tree canopy and nut yield $(\mathrm{r}=-0.61)$. The results showed that nuts per tree, hermaphrodite flowers per panicle and pollen grain fertility were positively and significantly correlated with each other. Days to flower anthesis, weight of the whole fruit and leaf size were negatively correlated with nuts per tree, hermaphrodite flowers per panicle and pollen grain fertility. However, leaf size had significantly positive and highly significant relationships with nut weight and weight of the whole fruit. Nuts per panicle, nuts per tree, hermaphrodite flowers per panicle and pollen grain fertility were highly significant and positively correlated with nut yield, while leaf size slightly correlated $(\mathrm{P}<0.05)$ with the nut yield. Highly significant negative correlations were recorded between nut yield and days to anthesis and tree canopy. Association between nut weight and nut yield was positive but insignificant. Traits such as nuts per panicle, nuts per tree and hermaphrodite flowers per panicle were highly significant and negatively correlated with nut weight. Meanwhile, weight of the whole fruit was positive and significantly correlated with nut weight, suggesting that genotypes with large apples tended to produce large nuts.

Table 2 is the combined summary of direct and indirect effects, effect coefficients and residuals of nine agronomic traits on cashew nut yield. Figure 1 shows the diagrammatic representation of the path analysis. The results showed that nut weight; nuts per panicle, nuts per tree, hermaphrodite flowers per panicle, pollen grain fertility and leaf size had significant positive direct path coefficients with nut yield. The direct effects of tree canopy and weight of the whole fruit was negatively significant, while direct effect of days to flower anthesis was negative and insignificant. Nuts per tree with the

Table 1. - Phenotypic correlation coefficients among 10 agronomic traits in cashew.

\begin{tabular}{|c|c|c|c|c|c|c|c|c|c|c|}
\hline & NWT & NNP & NNT & HFP & PGF & DFA & TCS & WWF & LSZ & NYT \\
\hline NWT & 1.000 & & & & & & & & & \\
\hline NNP & $-0.608 * *$ & 1.000 & & & & & & & & \\
\hline NNT & $-0.428 * *$ & $0.797 * *$ & 1.000 & & & & & & & \\
\hline HFP & $-0.463 * *$ & $0.788 * *$ & $0.768 * *$ & 1.000 & & & & & & \\
\hline PGF & -0.239 & $0.620 * *$ & $0.73 I^{* *}$ & $0.711 * *$ & 1.000 & & & & & \\
\hline DFA & 0.242 & -0.147 & $-0.277^{*}$ & $-0.254^{*}$ & $-0.353^{* *}$ & 1.000 & & & & \\
\hline TCS & 0.207 & $-0.291^{*}$ & $-0.287^{*}$ & $-0.532 *$ & $-0.472^{* *}$ & 0.142 & 1.0000 & & & \\
\hline WWF & $0.867 * *$ & $-0.461 * *$ & $-0.255^{*}$ & $-0.398 * *$ & -0.100 & 0.060 & 0.243 & 1.000 & & \\
\hline LSZ & $0.272 *$ & $-0.509 * *$ & -0.228 & $-0.453 * *$ & -0.143 & -0.173 & -0.209 & 0.797 ** & 1.000 & \\
\hline NYT & 0.108 & $0.844^{* *}$ & $0.988^{* *}$ & $0.863^{* *}$ & 0.701 ** & $-0.394 * *$ & -0.610 *** & -0.112 & $0.271^{*}$ & 1.000 \\
\hline
\end{tabular}

*: significant at $0.05, * *$ : significant at 0.01 . 
O.M. Aliyu·Silvae Genetica (2006) 55-1, 19-24

Table 2. - Path coefficient analysis (direct, indirect and residual effects) of nine agronomic traits on nut yield in cashew.

\begin{tabular}{llllllllllllll}
\hline & NWT & NNP & NNT & HFP & PGF & DFA & TCS & WWF & LSZ & I & C & E \\
\hline NWT & $\underline{0.317}$ & -0.407 & -0.332 & 0.091 & 0.022 & 0.002 & 0.009 & 0.077 & 0.317 & -0.221 & 0.096 & 0.012 \\
NNP & 0.223 & $\underline{0.414}$ & 0.691 & 0.349 & 0.342 & -0.134 & -0.299 & -0.442 & -0.324 & 0.406 & 0.820 & 0.024 \\
NNT & -0.024 & 0.571 & $\underline{0.578}$ & 0.363 & 0.238 & -0.247 & -0.141 & -0.321 & -0.029 & 0.409 & 0.9871 & 0.001 \\
HFP & -0.032 & 0.046 & 0.322 & $\underline{0.419}$ & 0.132 & 0.002 & -0.023 & -0.035 & -0.011 & 0.402 & 0.821 & 0.042 \\
PGF & -0.017 & 0.037 & 0.285 & 0.394 & $\underline{0.490}$ & -0.342 & -0.246 & -0.009 & -0.023 & 0.079 & 0.569 & 0.132 \\
DFA & 0.017 & -0.037 & -0.070 & -0.034 & -0.208 & $\underline{-0.008}$ & 0.006 & 0.005 & -0.004 & -0.325 & -0.333 & -0.061 \\
TCS & 0.015 & -0.017 & -0.173 & 0.150 & -0.068 & -0.242 & $\underline{-0.434}$ & 0.161 & 0.104 & -0.070 & -0.503 & -0.107 \\
WWF & 0.246 & -0.027 & -0.065 & -0.236 & -0.114 & 0.121 & -0.105 & $\underline{-0.303}$ & 0.396 & 0.215 & -0.088 & -0.024 \\
LSZ & 0.416 & 0.030 & -0.058 & 0.051 & -0.021 & -0.214 & -0.291 & 0.229 & $\underline{0.383}$ & 0.109 & 0.525 & 0.146 \\
\hline
\end{tabular}

Total residual effects $=0.165$., Underlined figures are the direct path coefficient values.

I: Total indirect of effects; C: Efficient coefficient; E: Residual effects.

highest correlation coefficient also had the highest direct path coefficient $\left(P_{3,10}=0.58\right)$ with nut yield. The indirect effects of nuts per tree through nuts per panicle and hermaphrodite flowers per panicle and pollen grain fertility were significant and positive. The highest indirect path coefficient of nuts per tree was through nuts per panicle with value of 0.57 . It is also important to note that the total indirect effect $(I=0.41)$ of this trait was the highest. Nut weight which has insignificant positive association with cashew nut yield in the correlation coefficient analysis was found to show significant direct effect with cashew nut yield $\left(P_{1,10}=0.317\right)$ in path coefficient analysis, but its indirect effects through nuts per tree and nuts per panicle were negative and significant. Besides leaf size with significant and positive indirect path coefficient, indirect effects of nut weight through other variables was negligible.

Significant positive indirect effects of nuts per panicle were recorded through nuts per tree, hermaphrodite flowers per panicle, pollen grain fertility and nut weight, while its indirect effects through leaf size, weight of the whole fruits and tree canopy were negatively significant. The total indirect effects of this yield related trait was positive $(I=0.41)$. Hermaphrodite flowers per panicle had total indirect effects of $(I=0.40)$, with only its indirect effect through nuts per panicle significant, while others were negligible. However, the indirect effects of pollen grain fertility through days to flower anthesis and tree canopy were negatively significant, but positive through nuts per tree and hermaphrodite flowers per panicle. The indirect effects of days to flower anthesis was significant and negative $(I=-0.33)$. Both direct and indirect effects of days to flower anthesis through other variables were negligible except through pollen grain fertility with indirect path coefficient of -0.21 . Weight of the whole fruits had significant positive indirect effects on nut yield through nut weight and leaf size and its total indirect effects was $(I=0.22)$. Although leaf size had positive and significant indirect effects on cashew nut yield through nut weight and weight of the whole fruits, its indirect effect through tree canopy was however negative.

\section{Discussion}

Generally, the nature of inter trait correlations may enhance or retard the selection progress. A positive rela-
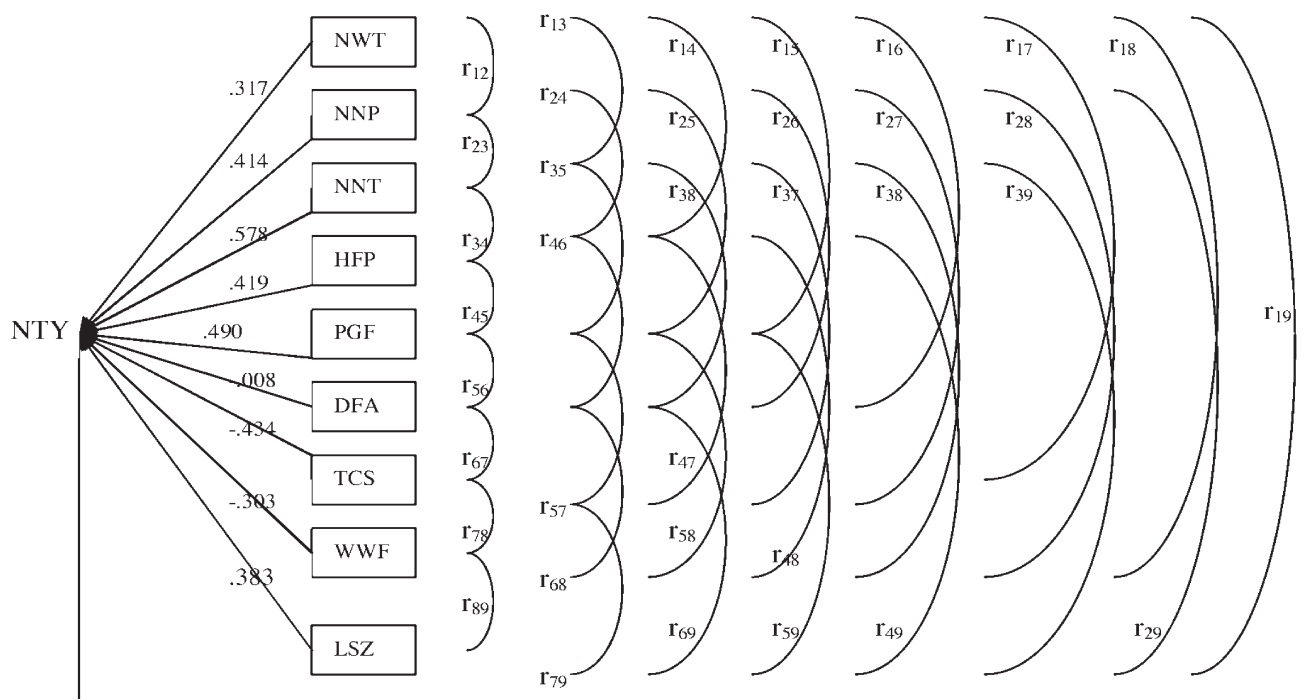

Residual effect $(0.165)$

Figure 1. - A path analyses diagram of nut yield and yield components of cashew. 
tionship indicates that the selection for improvement in one of the yield components would result in concomitant increase in one or more components. This type of relationships was recorded mostly among reproductive (nuts and floral) traits in this study. Positively and highly significant relationships among nuts per panicle, nuts per tree, hermaphrodite flowers per panicle, pollen grain fertility and nut yield suggest that nut yield can be improved through selection for these yield components. The significant positive correlations between nuts per panicles and nuts per tree and hermaphrodite flowers per panicle were in accordance with the reports of RAO (1974) and MURTHY et al. (1984). Improvement of cashew nut yield can therefore be achieved through selection of these highly correlated characters as increase in mean value of any one of the characters would significantly increase the means of others (PEDRO DE AzEVEDo et al., 1998). Insignificant association between nut weight and nut yield, indicated that yield improvement through direct selection of nut weight as a single character would be impractical. However, path analysis showed that nut weight had direct influence on yield and indirect significant effect through leaf size. The insignificant relationships between nut weight and nut yield in this study was contrary to the negatively significant association reported by NoRTHWOOD (1966). But similar negative influence of nut weight on nuts per tree and nuts per panicle were shown (Table 1).

Although, other perennial species have shown positive correlations between fruit production and diameter of the canopy (GLENDINNING, 1966; Singh DhaliWAL, 1968; GARCIA and NiCOLELlA, 1985), negative relationships between tree canopy and nut yield showed that cashew trees with large canopies tend to produce lower yield. MASAWE (1994) and MASAWE et al. (1998) reported similar observations on cashew in Tanzania. This result suggests that cashew trees with small canopies are likely to produce higher yield per unit area. NAMBIAR (1977) reported that cashew trees with excessive vegetative growth and large canopies were less productive than those with the medium-sized canopies. In addition, MARTIN and KASUGA (1995) reported that individual tree yield was highly variable and poorly correlated with density and canopy ground cover area.

Significant relationship between leaf size and nut yield suggests that leaf surface area plays significant role in dry matter production during fruit development and genotypes with large leaves tend to produce large fruit (apple and nut) (AlrYu, 2004). The influence of the relationships between leaf size and nut yield would be better amplified by nut weight as shown in Tables 1 and 2 . These two characters (leaf size and nut weight) could be regarded as secondary component characters because of their significant indirect correlations and would play important role in the improvement of cashew nut yield. FALCONER (1972) and MARIOTTI (1985) remarked that high genetic covariance estimates, genetic correlations and heritability benefit indirect selection of character.

Knowledge of complex relationships between nut weight and nut yield would be essential to effectively develop cashew varieties that combine moderately high yielding and good kernel quality in terms of size and colour. Although these characters showed insignificant relationship in the correlation analysis, path analysis revealed direct significant effect of the former on nut yield. Hybridization and recurrent selection method are the appropriate breeding techniques that can achieve meaningful progress in the improvement of cashew nut yield without compromising quality in this circumstance. SENA et al. (1994) reported positive association between nut weight and nut yield, while SALLEH et al. $(1989 a, 1989 b)$ recorded negative correlation between nuts per tree and nut weight as obtained in this study. However, it would be further desirable that appropriate selection indices may be formulated so that advance in one yield component is not nullified by deterioration in another.

However, the discrepancies in the results of the association between nut weight and nut yield among different authors may be attributed to differences in the advance stage of cashew population used for each of the respective studies, the pleiotropic gene effect and nature of past selection methods adopted in the previous yield improvement programme in each environment (FALCONER, 1972).

To effectively carry out improvement in cashew nut yield, selection procedure or approach could be adopted by ejecting all individuals that fail to come up to a certain standard for each yield components regardless of their values for any other (FALCONER, 1972). Although single character selection can improve yield, yet long range yield improvement is likely to result from improvement in all those characters that affect the expression of nut yield components. Six characters (nuts per panicle, nuts per tree, hermaphrodite flowers per panicle, pollen grain fertility, nut weight and leaf size) will ultimately have a favourable influence on the cashew nut yield either directly as primary yield components or indirectly through other secondary yield components. It has been shown, that the most rapid improvement of economic value is expected from selection applied simultaneously to all the component characters together, with appropriate weight being given to each character according to its relative economic importance, its heritability and the genetic correlations between the different characters (HAZEL and LUSH, 1942; HAZEL, 1943).

In summary, characters such as nuts per panicle, nuts per tree, hermaphrodite flowers per panicle and pollen grain fertility could be regarded as primary yield components, while nut weight and leaf size are secondary components through which indirect selection could be applied. While improvement in cashew nut yield could be rapidly achieved through selection of the correlated characters, however, improvement on nut and kernel quality would be better accomplished through hybridization.

\section{References}

ADAms, M. W. (1967): Basis of yield component compensation in crop plants with special reference to the field bean, Phaseolus vulgaris. Crop Science 7: 505-510. 
AlIYU, O. M. (2004): Characterization and compatibility studies in cashew (Anacardium occidentale L.). Ph. D. Thesis, University of Ilorin, Ilorin, Nigeria.

BEHRENS, R. (1998): About the spacing of cashew nut trees. Proceeding of the International Cashew and Coconut Conference, 17-21 February 1997, Dar es Salaam, Tanzania. BioHybrids International Ltd., Reading, UK, pp. 48-52.

Draper, N. R. and H. SMith (1967): Applied regression analysis. John Wiley and Sons Inc., New York.

EsAn, E. B. and S. S. OMOLAJA (2002): Genotypic association, path analysis and pluck quality value in tea (Camellia sinensis (L.) O. Kuntze). Tropical Agriculture, 79: 100-104.

FALCONER, D. S. (1972): Introduction to quantitative genetics. Robert MacLehose and Co. Limited, Glasgow, UK.

Freitas, B. M. and R. J. PAXTON (1996): The role of wind and insects in cashew (Anacardium occidentale L.) pollination in North Eastern Brazil. Journal of Agricultural. Science 126: 319-326.

Garcia, J. R. and G. NiCollela (1985): Correlacao entre algumas medidas dendrometricas, origins geneticase producao de frutos em cacueiros. Revista Theobroma 15: 113-124 (in Portuguese).

GLendinNing, D. R. (1966): Further studies on the relationships between growth and yield in cocoa varieties. Plant Breeding Abstract 36: 591.

GRAFIUS, J. E. (1960): Does overdominance exist for yield in corn? Agronomy Journal 52: 361.

HAZEL, L. N. (1943): The genetic basis for constructing selection indexes. Genetics 28: 476-490.

HAZEL, L. N. and J. L. LuSH (1942): The efficiency of three methods of selection. Journal of Heredity 33: 393-399.

IBPGR (1986): Descriptors for cashew (Anacardium occidentale L.). International Board for Plant Genetic Resources, Rome, Italy.

Ishaq, M. N., C. A. EcheKwu, P. E. Olorunj, U. S. Gupta and S. M. MisARI (2000): Correlations and path coefficient analysis in sugarcane (Saccharum officinarium L.). Nigerian Journal of Genetics 15: 22-28.

JACKSON R. E. (1967): The study of variation from year to year. Experimental Agriculture 3: 175-182.

KIM, J. O. and F. J. KOHOUT (1975): Analysis of variance and covariance. pp. 383-397 in SPSS: Statistical Package for the Social Sciences, $2^{\text {nd }}$ Ed., edited by N. H. NIE et al., McGraw-Hill Book Co., New York.

LI, C. C. (1981): Path analysis - a primer. The Boxwood Press, Pacific Groove, CA, USA.

MARIOTTI, J. A. (1985): Fundamentos de Genetica Biometrica-Applicaciones al Mejoramento Genetico Vegetal. Organizacion de los Estados Americanos, Washington, DC.

Martin, P. J. and L. J. KASUga (1995): Variation in cashew tree yield in South-east Tanzania and the implication for management of cashew smallholding. Tropical Agriculture 72: 261-268.

Martin, P. J., L. J. Kasuga and R. A. Bashiru (1998): Cashew farming upgrading: agronomic options for cashew production by smallholder farmers in Tanzania. Experimental Agriculture 34: 137-152.

MASAWE, P. A. L. (1994): Aspect of breeding and selecting improved cashew genotypes (Anacardium occidentale L.). Ph. D. Thesis, University of Reading, UK.

Masawe, P. A. L., E. P. Cundall and P. D. S. Caligari (1998): Performance in South-eastern Tanzania of local cashew germplasm and selected clones. Proceeding of International Cashew and Coconut Conference, 17-21
February 1997, Dar es Salaam, Tanzania. BioHybrids International Ltd., Reading, UK, pp. 146-150.

McNeal, F. H., E. P. Smith and M. A. Berg (1974): Plant height, grain yield, and yield component relationships in spring wheat. Agro. Jour. 66: 575-578.

Mitchell, J. D. and S. A. MoRI (1987): The cashew and its relatives (Anacardium, Anacardiaceae). Memoirs of the New York Botanical Gardens English 42: 1-76.

Murthy, K. N., K. K. Vijaya, R. S. N. Pillai and P. M. KuMARAN (1984): Flowering behaviour and correlation studies in cashew. In: Abstract of Proceedings of the International Cashew Symposium, Cochin, Kerala, India. 12-15 March 1979.

NaKasone, H. Y. and R. E. PAull (1998): Tropical Fruits. CAB International, Oxford, UK.

NAmbiar, M. C. (1977): Cashew. pp. 461-477 in Ecophysiology of Tropical Crops, edited by P. D. T. Alvins and T. T. KozLOwski. Academics Press, New York, U.S.A.

NoRTHwood, P. J. (1966): Some observations of flowering and fruit-setting in cashew (Anacardium occidentale L.). Tropical Agriculture 43: 35-24.

OHLeR, J. G. (1979): Cashew. Koninklijk Instituut voor de Tropen Teskin, Zutphen Co., Amsterdam, The Netherlands, 260p.

Pedroza de Azevedo, D. M. P., J. R. Crisostomo, F. C. G. Almeida and A. G. Rossetti (1998): Estimates of genetic correlations and correlated responses to selection in cashew (Anacardium occidentale L.). Genetics and Molecular Biology, Volume 21(3). [online]. Available online:http://www.scielo.br/scielo.php?script=sci_arttext\&pid=S1415-47571998000300019\&lng=en\&nrm= iso >. ISSN 1415-4757.

RAO, V. N. M. (1974): Crop Improvement of Cashew. Report All India Summer Institute on Improvement and Management of Plantation Crops, Mimeographed, 128-134.

SAlleh, H., T. B. ChAI and M. L. BAKRI (1989a): Seasonal variation in yield performance of 16 cashew clones on bris soil. MARDI Research Journal 17: 167-171.

SAlleh, H., T. B. Chai, N. A. WAHAB, M. L. BAKRI and T. A. ABIDAH (1989b): Identification of promising materials from a seedling population of cashew based on nut number and nut weight. MARDI Research Journal 17: 155-166.

Sena, D. K., P. C. Lenka, P. N. Jagadev and B. Sashikala (1994): Genetic variability and character association in cashew (Anacardium occidentale L.). Indian Journal of Genetics and Plant Breeding 54: 304-309.

SHOMARI, S. A. and C. P. TOPPER (2003): The importance of cashew in Tanzania and the role of supporting organizations. pp. 43-60. In: Knowledge Transfer for Sustainable Tree Crop Development, edited by C. P. TopPen and L. J. Kasuga. BioHybrids Agrisystems Ltd, Reading, UK.

Singh, R. K. and B. D. ChaudhaRY (1985): Biometrical methods in quantitative genetic analysis. Kalyani Publisher, New Delhi, India.

Singh Dhaliwal, T. (1968): Correlation between yield and morphological characters in Puerto Rican and Cohmnaris varieties of Coffea arabica L. Journal of. Agriculture of the University of Puerto Rico 52: 29-37.

Woodroof, J. G. (1967): Tree nuts Production, Processing, and Products, Vol. I. AVI Publishing Company and Incorporation, Westport CT. U.S.A.

WRIGHT, S. (1921): Correlation and causation. Journal of Agricultural Research 20: 557-587.

WRIGHT, S. (1923): Theory of path coefficients. Genetics 8: 239-255. 